\title{
Thermal, Electric and Durability Characterization of SuperCaps for Energy Back-up of Automotive ECU
}

\author{
S.Saponara, A.Bove, F.Baronti, R.Roncella, R.Saletti \\ Dip. Ingegneria dell'Informazione, University of Pisa \\ via G. Caruso 16, 56122, Pisa, Italy
}

\author{
D.Dente, E.Leonardi, M.Marlia, C.Taviani \\ MAGNA Closures - Motrol Division \\ via Francia 101, Guasticce, Livorno, Italy
}

\begin{abstract}
A new generation of mechatronic devices, such as the E-latch for door closure, is introduced in the automotive field to replace mechanical systems with electro-actuated parts with embedded electronic control unit (ECU) connected to the main vehicle network. Due to severe automotive safety-critical requirements an energy back-up solution is proposed, based on supercaps and boost converter, to ensure E-latch operation even in case of main battery failure. An in-depth thermal, electrical and durability characterization of the supercaps proves the suitability of the energy back-up unit for automotive applications.
\end{abstract}

Keywords-Electronic Control Unit (ECU); energy back-up; mechatronics; automotive door systems; E-latch; supercapacitors

\section{INTRODUCTION}

Automotive mechanical systems tend to be more and more often electronic controlled, to improve their performance and make new functions available. This trend is fully exploited in engine control, automatic transmission and for brake/steer assistance [1]-[4], but it has been applied at the door functions only for the rear mirror or the window lifter control [4]. Currently, the door open/closure system is still mechanical. The E-Latch is a new mechatronic device developed by Magna Closures in collaboration with the University of Pisa, in the AMDS (Advanced Mechatronic Door System) project framework. The E-latch is thus an interface between the passengers, the vehicle, and the door closure that is different from the standard mechanical door systems, as it is electrically actuated.

The E-latch can be seen as a node of the main vehicle network (e.g. connected through a LIN bus to the vehicle door subsytem), which manages all the functions concerning: reading the car handle and door status by means of Hall sensors or contact sensors; communicating with the car body computer by receiving commands from the users (lock, double lock, child lock, anti theft lock, release) and transmitting the door status or diagnostic info; driving the electric motor actuating the closure/release of the door (operating at $12 \mathrm{~V}$ nominal, $8 \mathrm{~V}$ minimum, with a current absorption in the order of several amperes); managing the main energy source (the automotive battery) or the back-up one (the supercaps and boost converter subsystem proposed in this paper).

The advantages of this new automotive device are many: a reduced weight and size of the mechanical-based door closure system; the flexibility, scalability and re-programmability of the unit that allows us to address different vehicle models and vehicle generations; the integration of the latch system in the vehicle networks to enable advanced safety features or new comfort functionalities. Unfortunately, the adoption of the Elatch, the architecture of which is discussed in Section II, is strongly challenged by the high level of reliability that is mandatory to achieve and particularly by the energy back-up system. The latter must guarantee the E-latch correct functionality (in particular the door release) even in case of a failure of the main vehicle battery, with minimum power consumption and weight/size overhead during normal vehicle operation. A new supercapacitor-based energy back-up system for the E-latch is proposed in this paper and described in Section III. It is then characterized in terms of thermal, electrical and durability performance in Section IV. Conclusions are finally drawn in Section V.

\section{E-LATCH: AN ADVANCED MECHATRONIC DOOR Closure System}

The E-Latch architecture is modular and is divided in two main units (Latch and Cinch) as it is shown in Fig. 1. Each unit includes: i) a micro-controller with LIN connectivity and multiple PWM output channels, ii) a high-voltage protection circuit to be directly connected to a $12 \mathrm{~V}$ power supply, iii) an integrated $\mathrm{H}$-bridge power MOS motor driver to actuate an electrical motor, iv) electrical motor and Hall sensors to actuate the door lock/release and monitor its status, respectively. The Latch sub-unit, see Fig. 2, is applicable to all the vehicles, since it manages the basic door locking and release (with special

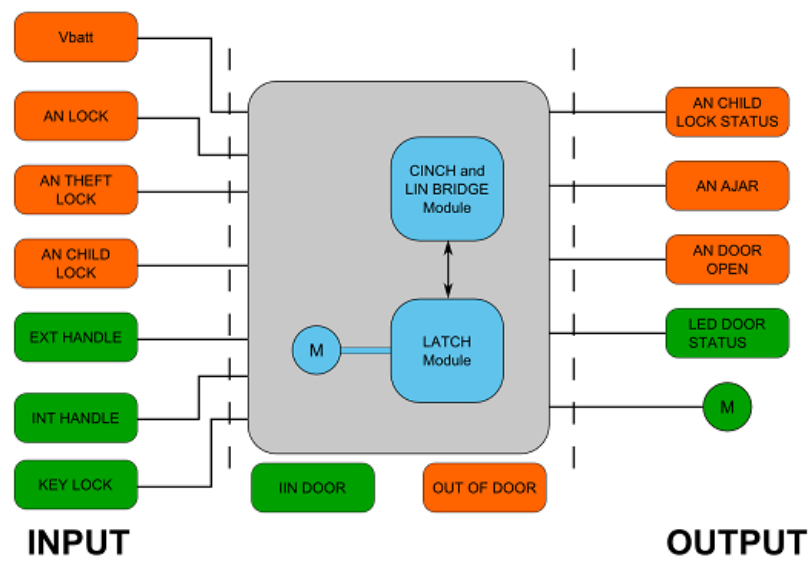

Fig. 1. E-latch block diagram with Latch and Cinch functions. 


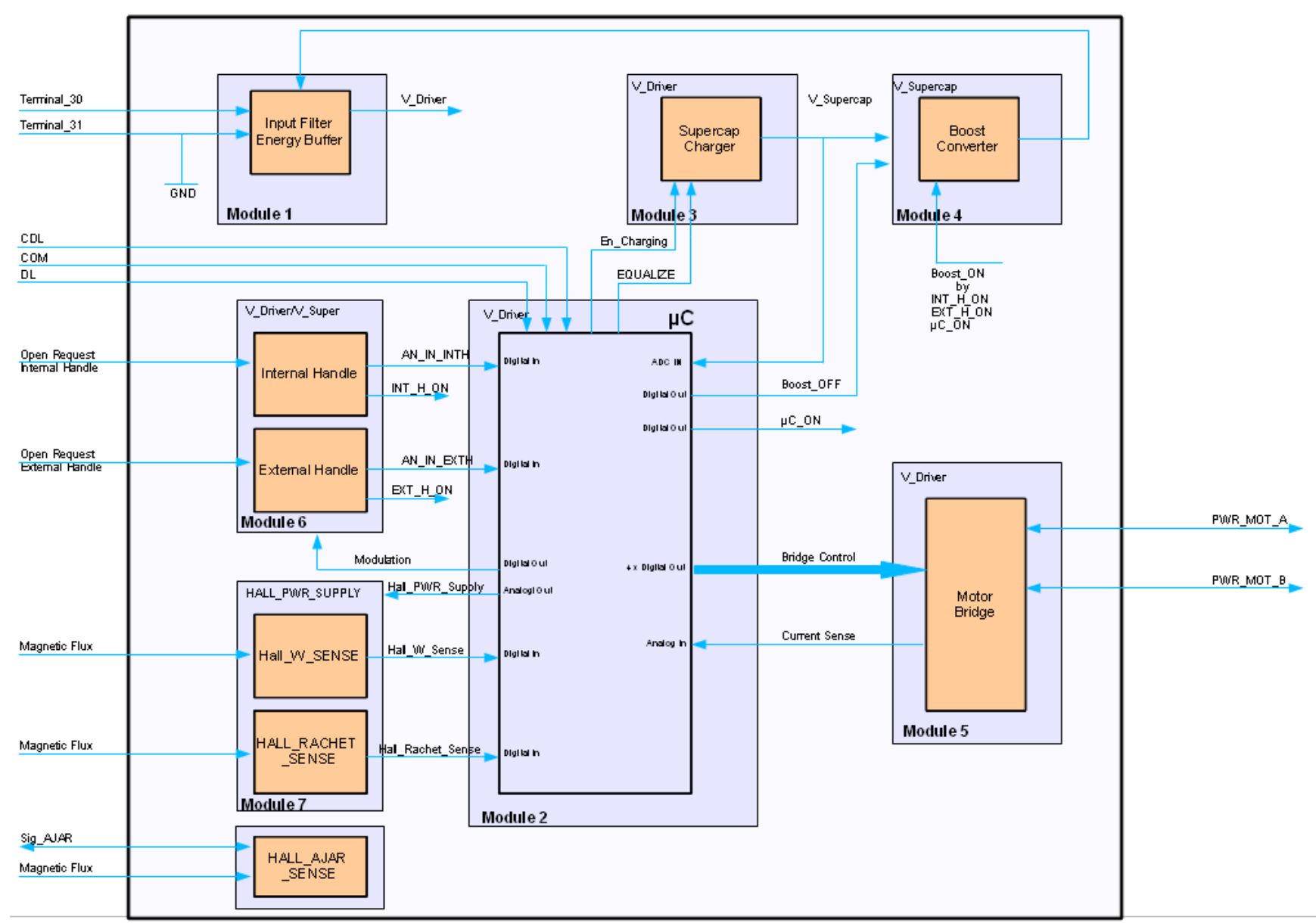

Fig. 2. Schematic diagram of the E-latch unit.

child-lock or double lock or anti-theft lock functionalities), whereas the Cinch is a special function, for premium vehicles, which automatically and gently closes the door when the door is leaved ajar by the user. The Latch sub-unit is connected to the body computer through a LIN port, while the Cinch module, when present, is a slave of the Latch one. The operating conditions of the E-latch are very harsh as it is expected for an automotive electronic system. The temperature spans from $-40^{\circ} \mathrm{C}$ to $80^{\circ} \mathrm{C}$, and thousands of open/lock cycles are expected in its lifetime. In addition, the electronics must withstand temperatures up to $130^{\circ} \mathrm{C}$ during the repainting

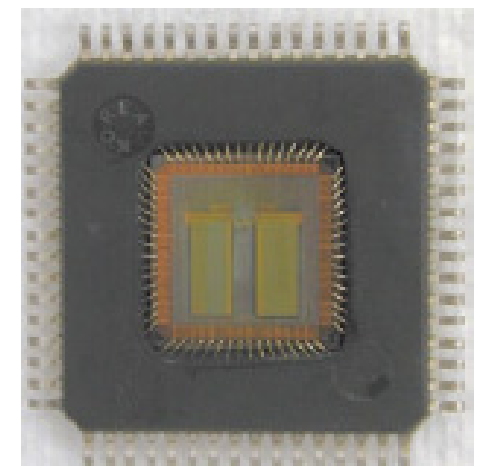

Fig. 3. The multi-die SIP device used in the E-latch. process of a vehicle door, as it is impractical to dismount the unit before repainting. The micro-controller and the protection circuitry are realized in the current E-latch implementation by a commercial SIP (System-on-a-Package) device with TQFP48 package, as shown in Fig. 3. The device integrates in the same package a digital die (a 16-b CPU with $20 \mathrm{MHz}$ clock frequency, several $\mathrm{kB}$ of FLASH and RAM memory, 16-b timer) and an analog one managing up to $18 \mathrm{~V}$ with on-chip temperature sensor, integrated low-drop out $2.5 \mathrm{~V} / 5 \mathrm{~V}$ voltage regulator, 10-b ADC, multi-channel PWM module for highside and low-side drivers, Hall sensor front-end, general purpose I/O pins.

The integrated motor driver incorporates a dual monolithic high-side driver and two low side switches, with Power MOSFET and intelligent signal/protection circuitry, all in a MultiPowerSO-30 package on electrically isolated leadframes and sustaining PWM motor control up to $20 \mathrm{kHz}$. The integrated motor driver receives $5 \mathrm{~V}$ inputs from the microcontroller and sustains motor driving up to $40 \mathrm{~V}$ and $30 \mathrm{~A}$, well beyond the requirements of the Latch or Cinch modules. The E-latch can work in two power modes: all the sub-units are working in full power mode; all the devices are off, with a residual current consumption of a few microampere, in powerdown mode (e.g. the vehicle is parked), where the ECU is waken-up by the watchdog timer or an external interrupt. The 
E-latch complies with the paradigm of the safety-critical electronic design as dictated by ISO/DIS 26262 [7].

As future market volumes for the E-latch are foreseen in millions of pieces, the proposed architecture could be improved by merging the Latch and Cinch units, currently partitioned in hardware, in a single 32-bit automotive microcontroller with 64 pins at least. Such devices, which represent the next generation of automotive processors [8], [9] and are available from different vendors (e.g. TX03 family by Toshiba, SPC56 family by STMicroelectronics, Tricore family by Infineon, Fado and Bolero families by Freescale), are often equipped with a double core thus increasing redundancy and hence fault-robustness. This way, the Cinch function or other advanced tasks could be added/removed by simply changing the firmware while the hardware of the E-latch ECU remains the same.

The microcontroller $12 \mathrm{~V}$ protection/power managing circuitry, the integrated motor drivers and the sparse glue logic could be realized single-chip as a custom ASIC, thus reducing the size and assembly cost of the E-latch. This new architecture can be the base for a revolution of the whole door system that, beside the E-latch, currently includes other two ECUs, the window lifter (integrating intelligent functionalities as the antipinch software) and the mirror control. Instead of having 3 ECUs, a single 32-bit powerful automotive microcontroller can manage all the software tasks and the communication with the car body computer, while distributing multiple applications specific ICs for sensor interfacing an motor driving, one for each function (mirror, window lifter, latch/cinch).

Whichever architecture is adopted, a key issue for the $E$ latch and in general for door ECUs is working properly even in case of a failure of the main battery: a supercapacitor-based energy back-up system has been designed to this aim and fully characterized in terms of electrical, thermal and durability performance in Sections III and IV.

\section{E-LATCH ENERGY BACK-UP SOLUTION}

As discussed before, an energy back-up system for automotive ECUs must operate in a temperature range from $-40^{\circ} \mathrm{C}$ to $80^{\circ} \mathrm{C}$, and withstand up to $130^{\circ} \mathrm{C}$ in case of door repainting. It is kept charged by the main vehicle battery in normal conditions. When the main battery fails, it should provide enough energy (typically tens of joule in short bursts of about $100 \mathrm{~ms}$, for about $100 \mathrm{~W}$ in power, $8 \mathrm{~V}-12 \mathrm{~V}$ in voltage and about $10 \mathrm{~A}$ in current, as a common actuator in this application requires) to ensure several door releases. The energy back-up system should be close to the E-latch ECU, robust to wiring failures, with minimum overhead in terms of cost, size and weight. Supercapacitor based energy storage systems are used in cars, but mainly for higher energy/power levels (tens of $\mathrm{kWh} / \mathrm{kW}$ ) [10]-[13]. Energy back-up solutions for low-power embedded systems are found in the literature mainly for ICT or consumer applications, not meeting the harsh environment requirements of automotive systems.

Therefore, we chose to explore the use of super-capacitors as storage devices in our application, because of the large temperature range and the high power density needed. Lithium batteries, widely adopted in automotive systems [10], [11] for electric or hybrid propulsion, would provide better energy density; however, a burst release of power is needed in the $E$ latch application (supercapacitors provide better power density [12], [13]) and the required temperature range is not covered by Lithium-based rechargeable batteries, typically limited up to $60^{\circ} \mathrm{C}$. There are Lithium batteries $\left(3.6 \mathrm{~V} \mathrm{Li}-\mathrm{SOCl}_{2}\right)$ that operate up to $150^{\circ} \mathrm{C}$, but they are non rechargeable and with high series resistance. Hence, these batteries seem more suited as very long-term energy storage devices, useful to keep the energy backup system charged during the winter parking of cabriolet cars or every time the main battery is disconnected for a long time. In conclusion, Electric Double Layer Capacitors (EDLC) with $2.5 \mathrm{~V}$ supply and tens of Farads, available from several vendors, were selected as energy storage devices for the energy back-up system of the E-latch.

The back-up system includes two EDLC supercapacitors ( $2.5 \mathrm{~V}$ nominal) connected in series plus an on-board $\mathrm{x} 2$ boost converter. This solution provides a nominal voltage of $10 \mathrm{~V}$ and a minimum of $8 \mathrm{~V}$ when the supercapacitors are not completely charged. As an example, two $2.5 \mathrm{~V} 10 \mathrm{~F}$ supercapacitors connected in series provide up to $62.5 \mathrm{~J}$, an energy sufficient for multiple emergency door releases. The switching architecture of the boost converter provides a high power efficiency in the voltage doubling. The PWM controller is realized with a commercial IC and small external RC components mounted on the same $\mathrm{PCB}$, which realizes a classic PID (proportional-integrative-derivative) control in the feedback loop. It should be noted that the micro-controller of the E-latch properly drives as open the boost converter switch SW1 and the feedback switch SW2 of Fig. 4, when the main battery voltage is present. The boost converter is thus normally off, the supercapacitors maintain their backup energy and even the resistors of the converter feedback are disconnected to save power. When the main battery fails, the micro-controller is supplied by the two supercapacitors in series $(5 \mathrm{~V})$, and the switches SW1 and SW2 are turned on, so that the door latch electric motor is supplied by the supercapacitors, should a door activation occur.

The switches SW1 and SW2 are realized with lowresistance MOS to maximize power efficiency. The main inductor also has a series resistance of few milliohms. The feedback is realized with a divider of the output voltage using two resistors of 1:11 ratio. Since a complete characterization of supercapacitors of few farads for energy back-up in automotive

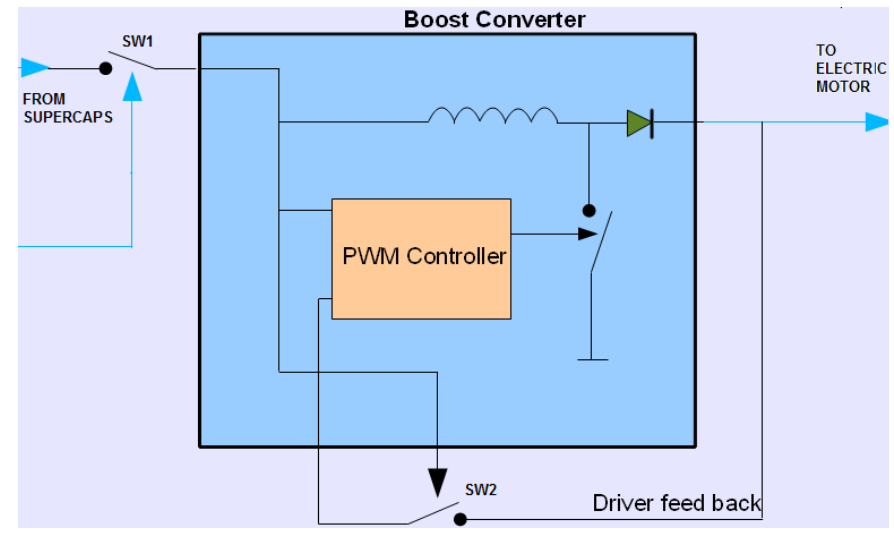

Fig. 4. Simplified schematic diagram of the boost-converter. 
ECU is missing in the literature, the devices to be used in the E-latch have been chosen after a thorough characterization campaign of $2.5 \mathrm{~V}$ EDLC supercapacitors in the range 10-25 F, provided from different vendors. For the sake of clarity and available space, all the experimental data are not reported. Instead, the characterization tests are described in Section IV.A and the results obtained for the selected device (a $18 \mathrm{~F}$ supercapacitor with $V_{\text {nom }}=2.5 \mathrm{~V}$ and $V_{\max }=2.7 \mathrm{~V}$ ) are reported in Section IV.B

\section{THERMAL, ElECTRICAL AND DURABILITY TESTS OF SUPERCAP FOR E-LATCH ENERGY BACK-UP}

The characterization of the supercapacitors was carried out with an experimental set-up consisting of a thermal chamber Binder MK53 for temperature controlled test, and a Keithley 2420 Source-Meter Unit. The basic procedures for measuring the capacitance value, the series resistance and the leakage resistance of a supercapacitor are the same commonly adopted in the literature [13]-[16]. Instead, the testing plan that specifies the type of tests to be carried out, their duration and repetition frequency, the values for current, temperature and voltage, is not provided by a standard procedure or referenced in the literature, but it is the result of the experience of Magna Closures on the characterization/verification of automotive door electronic systems.

\section{A. Testing Plan}

Let us define $C$ as the supercap capacitance, $V_{\text {nom }}$ the nominal voltage, $V_{\max }$ the maximum allowed voltage, $V_{\text {ref }}=0.9^{*} V_{\max }=2.43 \mathrm{~V}$ and $I_{\text {ref }}=C^{*} V_{\text {ref }} / 30=1.62 \mathrm{~A}$. The following tests have been carried out.

Constant-current charge/discharge capacitance test: the device is charged at $23^{\circ} \mathrm{C}$ for 3 cycles at a constant current $I_{\text {test }}=I_{\text {ref }} / 4=0.405 \mathrm{~A}$ up to $V_{\text {ref, }}$, then it is kept at this constant voltage for $10 \mathrm{~s}$ and then is completely discharged at constant current $I_{\text {ref }} / 4$; the 3-cycle test is repeated with current values of $I_{\text {ref }} / 2=0.81 \mathrm{~A}$ and $2 I_{\text {ref }}=3.24 \mathrm{~A}$. The supercap capacitance values in charge mode and in discharge mode are calculated by measuring the time $T_{\text {test }}$ of the charge and discharge phases, averaged over the 3 cycles, according to the formula: $C=I_{\text {test }} * T_{\text {test }} / V_{\text {ref. }}$. Two cycles carried out at different currents are shown in Fig. 5.

Constant-current ESR test: the supercap series resistance

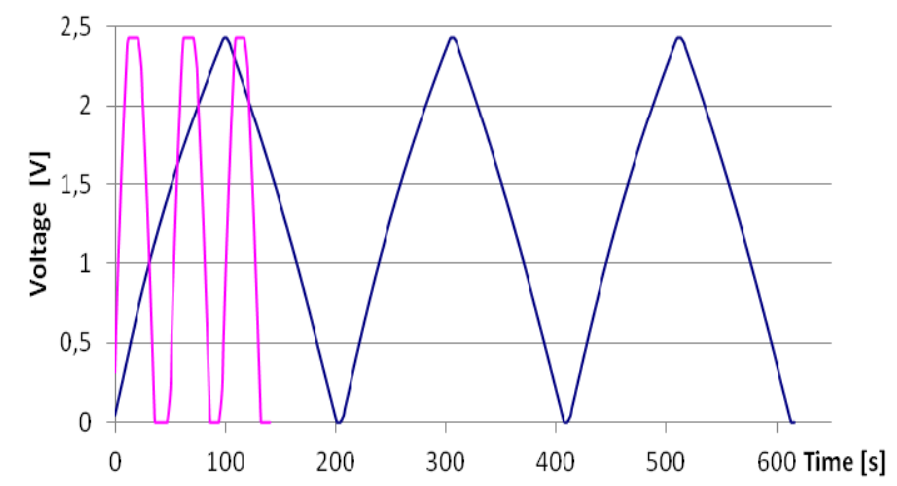

Fig. 5. Constant current charge/discharge test (blue: 0.405 A; pink: 3.24 A).

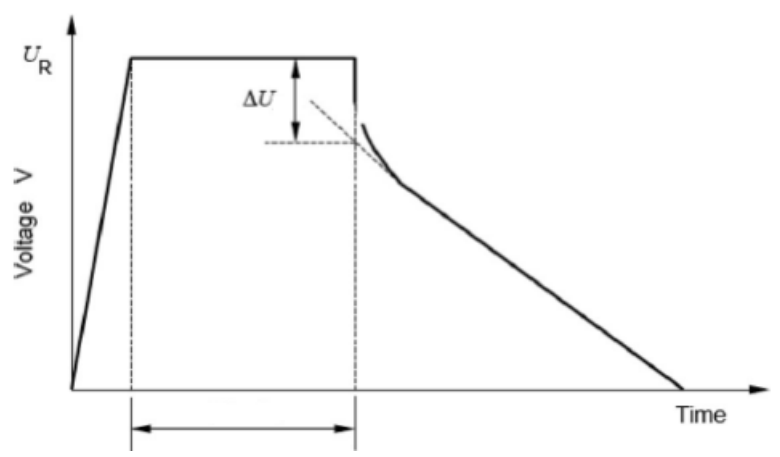

Fig. 6. ESR evaluation from constant-current discharge test

(ESR) has a visible effect during the above described charge/discharge tests at the start of the discharge phase, where the current step determines a voltage drop, as seen in Fig. 6. Dividing the voltage drop $\Delta U$ by the constant discharge current gives the ESR value.

Leakage test: the supercap tends to loose charge because of the auto-discharge; this phenomenon is modeled as a parallel timevariant leakage resistance [14], [15]. The super-capacitor is charged from 0 to $V_{\text {ref }}$ at $23^{\circ} \mathrm{C}$ and is kept at such voltage value for 3 hours. The capacitor current $I_{\text {leak }}$ needed to hold the voltage constant is the leakage current. The parallel resistance $R_{p}$ is the ratio $V_{\text {ref }} / I_{\text {leak }}$ and it is calculated by sampling $I_{\text {leak }}$ after $30 \mathrm{~min}, 1 \mathrm{~h}, 2 \mathrm{~h}$ and $3 \mathrm{~h}$. This test is usually repeated at different temperatures and for different durations.

Technology spreading and thermal tests: the leakage, ESR and capacitance tests are repeated using different samples of the same device to evaluate the technology spreading. The tests are also repeated on the same super-capacitor at different temperatures to determine the temperature dependence of the capacitance, ESR and leakage values.

Durability-temperature test: after 10 charge/discharge training cycles at $1 \mathrm{~A}$, the supercap is characterized at $23^{\circ} \mathrm{C}$ using the above described procedure to determine the ESR, leakage and capacitance values. This is the starting point of a durability test. A loop of 52 cycles is repeated. The loop consists of a first charge from $V_{\max } / 2$ to $0.9 V_{\max } ; 50$ charge/slow discharge cycles between $90 \%$ and $80 \%$ of $V_{\max }$ with a charging current of $I_{\text {ref }} / 20=80 \mathrm{~mA}$ and a discharge current of $10 \mathrm{~mA}$ follow; 1 last charge/fast discharge cycle between $90 \%$ and $70 \%$ of $V_{\max }$ with a charge current of $80 \mathrm{~mA}$ and a discharge of $I_{\text {ref }} / 2=800 \mathrm{~mA}$ completes the loop. The entire loop is then repeated 60 times. Such tests are repeated at $25^{\circ} \mathrm{C},-40^{\circ} \mathrm{C}$ and $80^{\circ} \mathrm{C}$ for a total of about 10000 cycles. The basic ESR-capacitance-leakage characterization at $23^{\circ} \mathrm{C}$ is carried out after each temperature value, to explore if the durability test has caused performance degradation or not.

Durability-temperature test with voltage derating: The durability test is carried out as described above, but the voltage is derated and hence the charge/discharge is between $80 \%$ and $70 \%$ instead of $90 \%$ and $70 \%$ of $V_{\max }$ at the highest temperature of $80^{\circ} \mathrm{C}$.

Repainting test: after the usual training cycles at $1 \mathrm{~A}$ and the basic characterization at $23^{\circ} \mathrm{C}$ the repainting thermal cycle lasts 75 minutes. It consists of $15 \mathrm{~min}$ at $130^{\circ} \mathrm{C}$ followed by $60 \mathrm{~min}$ 


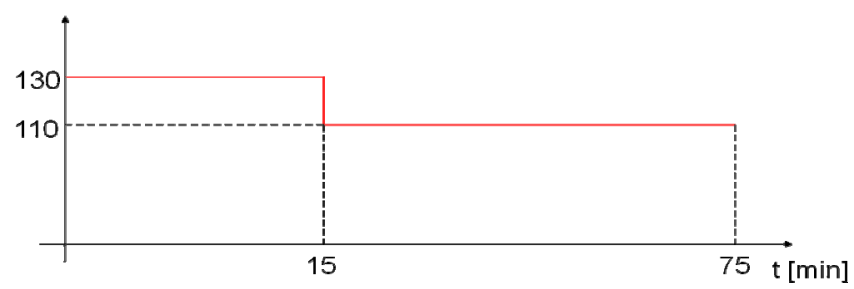

Fig. 7. Temperature $\left({ }^{\circ} \mathrm{C}\right)$ as a function of time in a repainting thermal test

at $110^{\circ} \mathrm{C}$, as it is shown in Fig. 7. The supercap is characterized again at $23^{\circ} \mathrm{C}$ after the test, to evaluate possible performance degradations due to the repainting cycle.

\section{B. Characterization Results}

Several EDLC supercapacitors from different vendors, with $2.5 \mathrm{~V}$ nominal voltage and capacitance ranging from 10 to $25 \mathrm{~F}$, where tested according to the procedures described in Section IV.A. We report here the main results obtained for the selected device, a $18 \mathrm{~F}$ EDLC, to proof that supercapacitors are suitable as energy back-up sources for the E-latch.

The capacitance and ESR tests at $23^{\circ} \mathrm{C}$ are shown in Fig. 5. The measured capacitance and resistance values are $17.69 \mathrm{~F}$ and $39.42 \mathrm{~m} \Omega$, respectively, at $0.405 \mathrm{~A}$, and $18.47 \mathrm{~F}$ and $18.92 \mathrm{~m} \Omega$ at $3.24 \mathrm{~A}$. The measured capacitance differs less than $2.6 \%$ from the nominal value of $18 \mathrm{~F}$; the series resistance is well below $100 \mathrm{~m} \Omega$. The time-variant parallel resistance extracted from the leakage test at $23^{\circ} \mathrm{C}$ is reported in Table I.

TABLE I. LEAKAGE RESISTANCE VERSUS TIME IN LEAKAGE TEST

\begin{tabular}{|c|c|c|c|c|}
\hline Time & $30 \mathrm{~min}$ & $1 \mathrm{~h}$ & $2 \mathrm{~h}$ & $3 \mathrm{~h}$ \\
\hline $\boldsymbol{R}_{p}$ & $1.8 \mathrm{k} \Omega$ & $5.4 \mathrm{k} \Omega$ & $50 \mathrm{k} \Omega$ & $1.25 \mathrm{M} \Omega$ \\
\hline
\end{tabular}

Repeating the tests on different samples of the same supercapacitor gives a spreading of the results limited to only a few percent, showing a good repeatability of the device characteristics. This is important because a good match of the devices makes negligible the charge equalization, a problem that arises when two units are mounted in series, as it happens in the E-latch circuit.

Instead, a higher dependence of the characterization

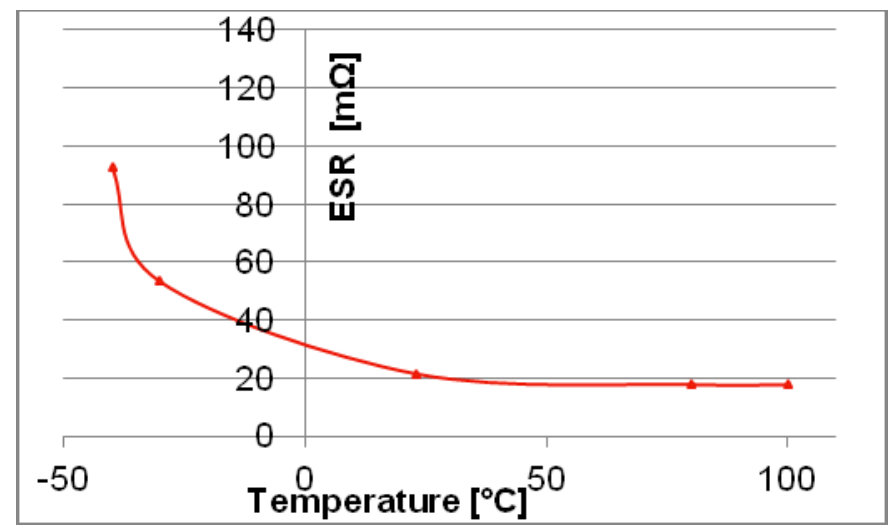

Fig. 8. Thermal dependance of the ESR, $I_{\text {test }}=0.81 \mathrm{~A}$

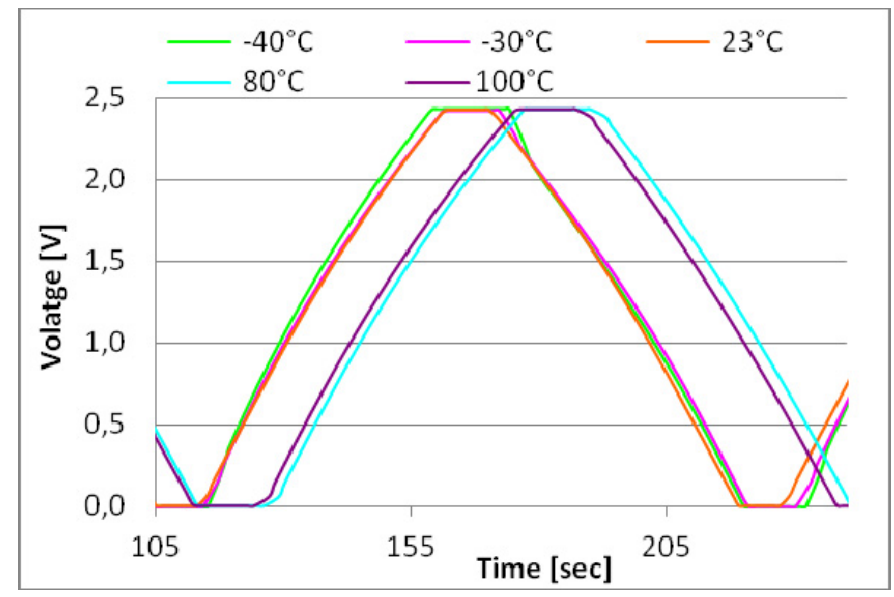

Fig. 9. Thermal dependance of the voltage slope in the charge-discharge test, $I_{\text {test }}=0.81 \mathrm{~A}$

parameters on the temperature has been found, as expected from theory and from results presented in the literature for much larger size supercapacitors (up to thousands of farad) [16]-[18]. As an example, Fig. 8 shows the ESR measured with a $I_{\text {test }}=I_{\text {ref }} / 2=0.81 \mathrm{~A}$ in the temperature range from $-40^{\circ} \mathrm{C}$ to $100^{\circ} \mathrm{C}$. The ESR value increases when the temperature decreases, but the series resistance remains always below $100 \mathrm{~m} \Omega$.

Since the capacitance value changes as a function of the temperature, the voltage slope of the charge/discharge test changes in its turn, as it is demonstrated in Fig. 9, where $0.81 \mathrm{~A}$ constant current tests at different temperatures are reported. The ESR behavior is monotonic with the temperature (see Fig. 8 ) and there is a large variation at low temperatures. Instead, the voltage slope value is weakly dependent on the temperature between $-40^{\circ} \mathrm{C}$ and room temperature (see Fig. 9). A difference in the slope of the diagrams in Fig. 9, and hence in the capacitance, is noticeable when going from room temperature to $100^{\circ} \mathrm{C}$. In particular, the slope and hence the capacitance increases with the temperature when going from $-40^{\circ} \mathrm{C}$ to $80^{\circ} \mathrm{C}$; instead, the capacitance decreases going from $80^{\circ} \mathrm{C}$ to $100^{\circ} \mathrm{C}$. This behavior agrees with the results published in the literature over larger super-capacitors (thousands of Farad), in which a non-linear behaviour of the capacitance with the voltage is found. In fact, the capacitance is composed of a fixed part $C_{0}$, that increases with the temperature, and a voltage dependent part, $C_{v}(V)$, that instead decreases when temperature increases.

The repainting test up to $130^{\circ} \mathrm{C}$ does not seem to affect the supercap performance. Indeed, the ESR, leakage current and capacitance values measured after the repainting thermal cycle of Fig. 7 shows that the capacitance and ESR are $17.61 \mathrm{~F}$ and $27.58 \mathrm{~m} \Omega$ respectively at $0.405 \mathrm{~A}$, and $17.85 \mathrm{~F}$ and $20.11 \mathrm{~m} \Omega$ respectively, at $3.24 \mathrm{~A}$. The leakage resistance varies from about $2 \mathrm{k} \Omega$ to $105 \mathrm{k} \Omega$ from $30 \mathrm{~min}$ to $3 \mathrm{~h}$. Such values are acceptable for the normal use of a super-capacitor in the $E$ latch. Similar findings are obtained after the durability tests, the results of which are reported in Table II.

The durability test has been described in detail in Section IV.A. It roughly consists of 10,000 cycles at temperatures from 
$-40^{\circ} \mathrm{C}$ to $80^{\circ} \mathrm{C}$. Current values of $0.405 \mathrm{~A}$ and $1.62 \mathrm{~A}$ are used for the re-characterization charge-discharge tests. It is found that the ESR only increases of a few percent and the capacitance decrease also is limited to a maximum of $10 \%$. These values are well acceptable for the application and demonstrate the suitability of the supercaps as energy back-up sources also after thousands of operating cycles.

TABLE II. PERFORMANCE DERATING AFTER DURABILITY TEST

\begin{tabular}{|c|c|c|c|c|c|}
\hline & \multicolumn{2}{|c|}{$\begin{array}{l}\text { ESR } \\
(\mathrm{m} \Omega)\end{array}$} & \multicolumn{2}{|c|}{$\begin{array}{c}\text { Capacitance } \\
\text { (F) }\end{array}$} & $\begin{array}{l}\text { Leakage } \\
\text { current }\end{array}$ \\
\hline & $0.405 \mathrm{~A}$ & $1.62 \mathrm{~A}$ & $0.405 \mathrm{~A}$ & $1.62 \mathrm{~A}$ & \\
\hline Initial & 26.52 & 19.27 & 17.52 & 17.85 & $2 \mu \mathrm{A}$ \\
\hline Max.derating & 27.35 & 19.47 & 16.04 & 16 & $50 \mu \mathrm{A}$ \\
\hline Change & $3.03 \%$ & $1.03 \%$ & $8.45 \%$ & $10.36 \%$ & - \\
\hline
\end{tabular}

A major effect is instead noticed on the leakage current: the $3 \mathrm{~h}$ leakage value increases from $2 \mu \mathrm{A}$ to $50 \mu \mathrm{A}$ after the durability test. It means that after 10,000 cycles the investigated supercapacitor would be completely autodischarged in about $10^{6} \mathrm{~s}$, i.e. around 11 days, if it was not recharged. However, this is not a problem when the main battery is working and it is continuously charging the supercapacitors (the boost converter is off). Should a main battery failure occur, the supercapacitors backup energy source would be needed to actuate the door release (e.g. to escape the car after a road accident) and hence 11 days before the complete autodischarge are still a long time considering the typical E-latch applications. On the contrary, that period is not compatible with a long-term park with the battery disconnected (e.g. during winter parking of some cars) because the supercap energy would be lost and the door could not be activated, without the main battery. In conclusion, the supercap energy source works as short-term and fails as long-term energy storage system, particularly with the ageing of the device.

\section{CONCLUSIONS AND LEASSON LEARNT}

A new generation of Electronic Control Unit (ECU), called E-latch, shows up on the car market. The mechanical door closure system is actuated by a motor controlled by an electronic system, with advantages in system modularity, scalability, cost, size and weight. Due to the severe automotive safety-critical requirements, an energy back-up solution is needed to ensure door release/closure also in case of main battery failure. A solution based on small-size super-capacitors and boost converter is proposed to this aim. An in-depth thermal, electrical and durability characterization of the supercaps proves the reliability of the energy back-up unit for automotive applications. The critical point is the selection of the energy storage device. A thorough measurement campaign demonstrates that the selected EDLC supercaps provide the required energy storage capability, with extended operating temperature range from $-40^{\circ} \mathrm{C}$ up to (non continuous) $130^{\circ} \mathrm{C}$, low series resistance (tens of milliohm) and leakage current, and low performance degradation even after 10,000-cycle durability test carried out at different current and temperature levels.

\section{ACKNOWLEDGMENT}

This work has partially been supported by Regione Toscana under AMDS project.

\section{REFERENCES}

[1] B. Flamings, "Automotive electronics", IEEE Vehicular Technology Magazine, vol.1, n.1 pp.40-42, 2006.

[2] F. Baronti, A. Lazzeri, R. Roncella, R. Saletti, S. Saponara, "Design and characterization of a robotized gearbox system based on voice coil actuators for a Formula SAE Race Car", IEEE/ASME Trans.on Mechatronics, vol. 18, n.1, pp. 53-61, 2013.

[3] N. Costantino et al., "Design and test of an HV-CMOS intelligent power switch with integrated protections and self-diagnostic for harsh automotive applications", IEEE Trans. on Industrial Electronics, vol.58, n.7, pp.27152727, 2011.

[4] F. Baronti, et al., "Design and verification of hardware building blocks for high-speed and fault-tolerant in-vehicle networks", IEEE Trans. on Industrial Electronics, vol.58, n.3, pp.792-801, March 2011.

[5] S. Saponara et al., "HV-CMOS Design and Characterization of a Smart Rotor Coil Driver for Automotive Alternators", IEEE Trans. on Industrial Electronics, vol.60, n.6, pp. 2309 - 2317, 2013

[6] Xiao Zhaoxia; Li Youcheng, "IEEE hardware design of automobile door with local interconnect network bus", IEEE Int. Conf. on Control, Automation and System Engineering (CASE) 2011, pp.1-4, July 2011.

[7] M. Hillenbrand et al., "Failure mode and effect analysis based on electric and electronic architectures of vehicles to support the safety lifecycle ISO/DIS 26262”, IEEE Int. Symp. On Rapid System Prototyping (RSP) 2010, pp. 1-7.

[8] A. Mayer, F. Hellwig, "System performance optimization methodology for Infineon's 32-bit automotive microcontroller architecture", 2008 Design, Automation and Test in Europe (DATE) Conf., pp. 962-966, 2008.

[9] G. Zhang, "Freescale automtoive microcontroller roadmap", August 2011, doc. n. FTF-AUT-F0783.

[10]M. Brandl et al., "Batteries and battery management systems for electric vehicles", 2012 Design, Automation and Test in Europe (DATE) Conf., pp. 971-976, 2012.

[11] M. Einhorn, F.V. Conte, C. Kral, J. Fleig, "Comparison, selection, and parameterization of electrical battery models for automotive applications", IEEE Trans. on Power Electronics, vol.28, n.3, pp.1429-1437, 2013.

[12]H. Gualous, D. Bouquain, A. Berthon, J.M. Kauffmann, "Experimental study of supercapacitor serial resistance and capacitance variations with temperature", Journal of Power Sources, vol.123, pp. 86-93, 2003

[13] Yi cheng Zhang, Li Wei, Xiaojun Shen, Haiquan Liang, "Study of supercapacitor in the application of power electronics", WSEAS Trans. on Circ. and System., n. 6, Vol. 8, pp. 508-517, June 2009.

[14]Jin Hyun Chang, F. P. Dawson, K. K. Lian, “A first principles approach to develop a dynamic model of electrochemical capacitors", IEEE Trans. on Power Electr., vol.26, n.12, Dec. 2011.

[15] N. Rizoug, P. Bartholomeüs, P. Le Moigne, "Modeling and characterizing supercapacitors using an online method", IEEE Trans. on Ind. Electronics, vol. 57, n. 12, pp. 3980-3990, Dec. 2010.

[16] H. Gualous, H. Louahlia, R. Gallay, "Supercapacitor characterization and thermal modelling with reversible and irreversible heat effect", IEEE Trans. on Power Electr., vol.26, n.11, pp.3402-3409, Nov. 2011.

[17] R. Kotz, M. Hahn, R. Gallay, "Temperature behavior and impedance fundamentals of supercapacitors", J. Power Sources, vol.154, no.2, pp.550 555, 2006.

[18] E.L. H. El Brouji et al., "Aging assessment of supercapacitors during calendar life and power cycling tests", IEEE Energy Conversion Congress and Exposition (ECCE), pp.1791-1798, 2009. 